\title{
Perceived Barriers of Incident Reporting Among Internists: Results from Hamad Medical Corporation in Qatar
}

\author{
Mouhand F.H. Mohamed ${ }^{1}$ Ibrahim Y. Abubeker ${ }^{2}$ Dabia Al-Mohanadi ${ }^{1}$ Ahmed Al-Mohammed ${ }^{1}$, \\ Abdul-Badi Abou-Samra1,3, Abdel-Naser Elzouki ${ }^{1,3,4}$ \\ ${ }^{1}$ Department of Internal Medicine, Hamad General Hospital, Hamad \\ Medical Corporation, Doha, Qatar \\ ${ }^{2}$ Department of Medicine, Brown Internal Medicine Residency, \\ Brown University, Providence, Rhode Island, United States \\ ${ }^{3}$ Department of Medicine, Weill Cornell Medical College, \\ Doha, Qatar \\ ${ }^{4}$ Department of Medicine, College of Medicine, Qatar University, \\ Doha, Qatar \\ Address for correspondence Abdel-Naser Elzouki, MD, PhD, \\ FACP, Department of Internal Medicine, Hamad General Hospital, \\ Hamad Medical Corporation, Doha, P.O Box, 3050, Qatar \\ (e-mail: nelzouki_1999@yahoo.com).
}

Avicenna J. Med. 2021;3:139-144.

\section{Abstract \\ Keywords \\ - occurrence variance accident \\ - OVA \\ - health care \\ - quality \\ - patient safety}

Background Adverse events (AE) are responsible for annual deaths that exceed deaths due to motor vehicle accidents, breast cancer, and AIDS. Many AE are considered preventable. Thus, AE needs to be detected and analyzed. Incident reporting systems (IRS) are crucial in identifying AE. Nevertheless, the incident report (IR) process is flawed with underreporting, especially from the physicians' side. This limits its efficiency in detecting AE. Therefore, we aimed to assess the practice and identify the barriers associated with incident reporting among internal medicine physicians in a large tertiary hospital through a survey.

Methods A cross-sectional descriptive study. We distributed an online survey to physicians working in the Internal Medicine Department of Qatar's largest tertiary academic institute. The questionnaire was validated and piloted ahead of the start of the trial. The response rate was $53 \%$.

Results A total of 115 physicians completed the survey; $59 \%$ acknowledged the availability of an institutional IRS. However, only $29 \%$ knew how to submit an online IR, and $20 \%$ have ever submitted an IR. The survey revealed that participants were less likely to submit an IR when they or a colleague is involved in the incident; $46 \%$ and $63 \%$, respectively. The main barriers of reporting incidents were unawareness about the IRS (36\%) and the perception that IR will not bring a system change (13\%); moreover, there exists the fear of retaliation (13\%). When asked about solutions, $57 \%$ recommended training and awareness, and $22 \%$ recommended sharing learnings and actions from previous IR.

Conclusions IRS is underutilized by internal medicine physicians. The main barrier at the time of the survey is the lack of training and awareness. Promoting awareness and sharing previous learning and actions may improve the utilization of the IRS. published online

August 31, 2021
DOI https://doi.org/

$10.1055 / \mathrm{s}-0041-1734386$ ISSN 2231-0770 (c) 2021. Syrian American Medical Society.

This is an open access article published by Thieme under the terms of the Creative Commons Attribution-NonDerivative-NonCommercial-License, permitting copying and reproduction so long as the original work is given appropriate credit. Contents may not be used for commercial purposes, or adapted, remixed, transformed or built upon. (https://creativecommons.org/licenses/by-nc-nd/4.0/). Thieme Medical and Scientific Publishers Private Limited A-12, Second Floor, Sector -2, Noida-201301, Uttar Pradesh 


\section{Introduction}

Adverse events (AE) are defined by good clinical practice (GCP) as "any untoward medical occurrence in a patient or clinical investigation subject administered a pharmaceutical product and which does not necessarily have a causal relationship with this treatment."1 Unfortunately, AE are relatively common and can be fatal. This is depicted in a systematic review by de Vries et al, which included over 74000 patient data and revealed an $\mathrm{AE}$ incidence of $9.2 \%$, with $6 \%$ being fatal. Surprisingly, $43.5 \%$ were deemed preventable. ${ }^{2}$

Incident reporting is crucial for patient care. The institute of medicine (IOM) and the World Health Organization (WHO) recommended the development of incident reporting systems (IRS) as means of studying, analyzing, and learning from AE. ${ }^{3,4}$ Following the IOM report in 1999, which highlighted AE in health care, many studies showed promising results utilizing the IRS to increase AE detection, in order to understand them better and implement preventive strategies. ${ }^{5}$

Underreporting of incidents in health care was reported to be as high as $96 \% .^{6-8}$ Physicians tend to report fewer incidents compared with other allied health care professionals. ${ }^{9-11}$ Previous studies explored possible barriers of underreporting with important learned lessons. ${ }^{6-9,11-13}$ Nevertheless, there is a paucity of data about the incident reporting behaviors among physicians and trainees in the Middle East. Thus, we planned this descriptive cross-sectional study to assess the physician's knowledge and experience with an IRS in Qatar's largest tertiary academic hospital, thereby identifying the perceived barriers of reporting incidents and planning to develop interventions that improve IRS utility and efficiency.

\section{Methods}

Research Designs, Study Setting, and Participants and Research Instrument and Consent

This was a cross-sectional descriptive study conducted at the internal medicine department of Hamad Medical Corporation (HMC), the largest tertiary care provider in Qatar. It is an academic institute that is accredited by the accreditation council for graduate medical education international (ACGME-I) and the Joint Commission International (JCI). The study population was a convenient sample of all active internal medicine physicians (175 trainees and 55 attendings) working at the HMC. The research instrument was an online questionnaire. Consent was taken from the participants ahead of enrollment in the study via invitation letters and information sheets, explaining the study purpose and the voluntary and confidential nature of the participation. The department chairman approved the study, and no formal institutional review board (IRB) approval was sought, as it was part of a quality improvement initiative.

\section{Questionnaire Development}

A short questionnaire was developed based on reviewing related literature. Essential questions were grouped, and then reviewed by a panel of physicians who worked at the internal medicine department and were involved in the corporate quality committee. Furthermore, we performed a pilot on 10 physicians who were later excluded from the study population. The questionnaire was readjusted, based on the pilot results, and reviewed again by the same panel that approved the final version. The questionnaire had 20 questions and underwent phases of validation; the readability level was of 9th grade.

\section{Questionnaire Content}

The survey included closed-ended questions with categorical outcomes related to demographic data, assessment of IRS awareness, IRS use, perceived barriers of IRS, and possible solutions to improve the utility of the IRS. In addition, the questionnaire included open-ended questions with a qualitative assessment, exploring other barriers to utilizing the IRS and exploring further suggestions.

\section{Questionnaire Delivery}

We sent an online survey in August 2018 to physicians (faculty and trainees) working under the internal medicine department at HMC. We limited the survey to internal medicine physicians, as this was a quality improvement initiative, with a plan of expanding this to other specialties in the future. We used the Survey Monkey website to disseminate the survey to the staff with three planned email reminders, in order to enhance participation. The target response rate was determined a priori as 92 responses or $40 \%$ (25-45\% based on the expected response rate, expected in studies targeting physicians). ${ }^{6}$

\section{Statistical Analysis}

We used summary descriptive statistics to depict participants' responses as our main analysis. Additionally, in secondary analysis, we used the Chi-square test to compare the frequency of responses between faculty and trainees. Jamovi program, version 1.1.9, was used for the statistical analysis.

\section{Results}

\section{Participant's Characteristics}

Two hundred and thirty physicians received the survey, 122 (53\%) responded to the survey, and 115 (50\%) completed the survey. The survey filling time was estimated to be 4 minutes duration. Out of the 115 participants, $71 \%$ were males and $29 \%$ females; the majority were trainees $(77 \%$ ) defined by being a resident or a fellow under the general internal medicine training and $23 \%$ were faculty, and $94 \%$ were from the main tertiary hospital (Hamad General Hospital [HGH]), and $6 \%$ were from secondary care hospitals ( - Table 1 ).

\section{Awareness and Experience with IRS}

Among all participants, $41 \%$ were not aware of the availability of the IRS, and $71 \%$ did not know how to submit an online incident report (IR). When asked about whether they have ever submitted an IR, only $20 \%$ did so. However, only $16 \%$ had submitted an IR in the last 12 months, and none had submitted more than three IR. Interestingly, 84\%, 66\%, and 70\% 
think that IRS is useful, transparent, and efficient, respectively ( - Table 2 ).

\section{Incident Reporting Culture}

The survey asked whether physicians would likely report an IR that involves self or a colleague. Interestingly, $46 \%$ would not file an IR if they were involved in the incident, and a more

Table 1 Participant characteristics ( $n=115$ completed the survey)

\begin{tabular}{|c|c|}
\hline Characteristics & Numerical count (\%) \\
\hline \multicolumn{2}{|l|}{ Survey recipients } \\
\hline Received the survey & $230(100)$ \\
\hline Completed the survey & $115(50)$ \\
\hline \multicolumn{2}{|l|}{ Sex } \\
\hline Male & $82(71)$ \\
\hline Female & $33(29)$ \\
\hline \multicolumn{2}{|l|}{ Job title } \\
\hline Consultant & $27(23)$ \\
\hline Fellow & $10(9)$ \\
\hline Resident & $78(68)$ \\
\hline \multicolumn{2}{|l|}{ Workplace } \\
\hline Hamad General hospital & $108(94)$ \\
\hline Al Wakra and Al Khor hospitals & $7(6)$ \\
\hline
\end{tabular}

significant fraction of $63 \%$ would not file an IR if a colleague or a friend was involved in the incident.

\section{Perceived Barriers to Incidents Reporting}

The survey asked participants to choose the most critical barrier to incident reporting. The main barriers were as follows: IRS availability unawareness in $36 \%$, inability to access IRS or insufficient knowledge about its access and usage (26\%), a perception that submitting an IR will not result in any change in the system (13\%), concern or fear of retaliation to oneself or colleagues (13\%), high workload (11\%), or belief that IR was not essential (2\%). The majority of the free-text responses highlighted a lack of training, fear of blame, and a perceived lack of anonymity.

\section{Enhancing Incident Reporting}

The survey asked participants to identify one effective intervention that improves the utilization of the IRS. As much as $57 \%$ of participants recommended training and awareness. In contrast, $22 \%$ recommended sharing learnings and actions from previous IR with the clinical staff as a means of enhancing the IRS utilization. Finally, 21\% recommended shortening the process of the IRS. Overall, $83 \%$ would attend an IRS training course, $57 \%$ of them would prefer an online course, and $43 \%$ would prefer attending an onsite course. Online courses were selected more often by faculty than trainees ( $85 \%$ vs. $43 \%, p=0.000$, - Table 2 ).

Table 2 Participants' responses to survey questions by groups

\begin{tabular}{|c|c|c|c|c|c|}
\hline \multirow{2}{*}{$\begin{array}{l}\text { Question } \\
\text { Are you aware of the availability of an incident } \\
\text { reporting system in our hospital? }\end{array}$} & \multicolumn{2}{|c|}{$\begin{array}{l}\text { Faculty (consultants } n=27) \text {, } \\
n(\%)\end{array}$} & \multicolumn{2}{|c|}{$\begin{array}{l}\text { Trainees (fellows } n=10 \text { and } \\
\text { residents } n=78), n(\%)\end{array}$} & \multirow{2}{*}{$\begin{array}{l}p \text {-Value } \\
0.98\end{array}$} \\
\hline & Yes $16(59 \%)$ & No $11(41 \%)$ & Yes 52 (59\%) & No 36 (41\%) & \\
\hline $\begin{array}{l}\text { Do you know how to submit an incident report } \\
\text { on the system? }\end{array}$ & Yes $9(33 \%)$ & No $18(67 \%)$ & Yes $24(27 \%)$ & No 64 (73\%) & 0.54 \\
\hline $\begin{array}{l}\text { Have you ever used the reporting system to } \\
\text { submit an incident report? }\end{array}$ & Yes $8(30 \%)$ & No $19(70 \%)$ & Yes $15(17 \%)$ & No $73(83 \%)$ & 0.15 \\
\hline $\begin{array}{l}\text { How many times did you use the reporting } \\
\text { system to submit an incident report in the last } \\
\text { year? a }\end{array}$ & $\begin{array}{l}\text { Zero times } 21 \\
(78 \%)\end{array}$ & $\begin{array}{l}1-3 \text { times } 6 \\
(22 \%)\end{array}$ & $\begin{array}{l}\text { Zero times } 75 \\
(85 \%)\end{array}$ & $\begin{array}{l}1-3 \text { times } 13 \\
(15 \%)\end{array}$ & 0.36 \\
\hline $\begin{array}{l}\text { In your own opinion is the reporting system } \\
\text { useful? }\end{array}$ & Yes 21 (78\%) & No $6(22 \%)$ & Yes 75 (85\%) & No 13 (15\%) & 0.36 \\
\hline $\begin{array}{l}\text { In your opinion is the reporting system } \\
\text { transparent? }\end{array}$ & Yes $18(67 \%)$ & No 9 (33\%) & Yes 58 (66\%) & No $30(34 \%)$ & 0.94 \\
\hline In your opinion is the reporting system efficient? & Yes 17 (63\%) & No $10(37 \%)$ & Yes 63 (72\%) & No 25 (28\%) & 0.39 \\
\hline $\begin{array}{l}\text { How likely are you to submit an incident report } \\
\text { when you commit an error? }\end{array}$ & Likely 16 (59\%) & $\begin{array}{l}\text { Less likely } 11 \\
(41 \%)\end{array}$ & Likely 46 (52\%) & $\begin{array}{l}\text { Less likely } 42 \\
(48 \%)\end{array}$ & 0.52 \\
\hline $\begin{array}{l}\text { How likely are you to submit an incident report } \\
\text { when your colleague/friend commits an error? }\end{array}$ & Likely 14 (52\%) & $\begin{array}{l}\text { Less likely } 13 \\
(48 \%)\end{array}$ & Likely 28 (32\%) & $\begin{array}{l}\text { Less likely } 60 \\
(68 \%)\end{array}$ & 0.058 \\
\hline $\begin{array}{l}\text { If the department of internal medicine arranged } \\
\text { an incident reporting training course, would you } \\
\text { be interested in attending it? }\end{array}$ & Yes $25(93 \%)$ & No $2(7 \%)$ & Yes $71(81 \%)$ & No 17 (19\%) & 0.14 \\
\hline $\begin{array}{l}\text { If yes, would you prefer an online or onsite } \\
\text { course? }\end{array}$ & Online $23(85 \%)$ & $\begin{array}{l}\text { Onsite } 4 \\
(15 \%)\end{array}$ & $\begin{array}{l}\text { Online } 43 \\
(49 \%)\end{array}$ & $\begin{array}{l}\text { Onsite } 45 \\
(51 \%)\end{array}$ & $0.000^{\mathrm{b}}$ \\
\hline
\end{tabular}

a No participant used reporting system more than three times; hence, other options were not presented in this table.

${ }^{\mathrm{b}}$ This result is hypothesis-generating and is not confirmatory. 
Table 3 Examples of participants' free-text responses to open-ended questions

\begin{tabular}{|c|c|}
\hline Question & Participants' comments \\
\hline $\begin{array}{l}\text { Are there any } \\
\text { other barriers? }\end{array}$ & $\begin{array}{l}\text { "The process should be blame-free." } \\
\text { "The perception that someone will be } \\
\text { harmed by reporting makes one do it in } \\
\text { very few circumstances only." } \\
\text { "Do not know how to use it. Usually, it } \\
\text { results in reactionary steps that make the } \\
\text { system worse without considering balanc- } \\
\text { ing measures." } \\
\text { "Complicated system." } \\
\text { "Long process." } \\
\text { "No feedback on actions taken for reported } \\
\text { incidents." }\end{array}$ \\
\hline $\begin{array}{l}\text { Any other } \\
\text { suggestions to } \\
\text { improve the } \\
\text { utilization of } \\
\text { the reporting } \\
\text { system? }\end{array}$ & $\begin{array}{l}\text { "Developing a safe environment for } \\
\text { reporting." } \\
\text { "Reassure the staff that it is mainly to } \\
\text { improve the system and not intended to } \\
\text { punish or harm any member of the staff." } \\
\text { "Reassurance about anonymity should be } \\
\text { done; perhaps the team should meet with } \\
\text { us to tell us about the process and taken } \\
\text { actions." } \\
\text { "Make it more transparent. Tell us who has } \\
\text { access to the information and whom he/ } \\
\text { she is sharing it with." } \\
\text { "Sharing previously learned actions in an } \\
\text { anonymous blame-free manner." "Being } \\
\text { part of incident report review committees." }\end{array}$ \\
\hline $\begin{array}{l}\text { How can we } \\
\text { actively promote } \\
\text { a blame-free cul- } \\
\text { ture of reporting } \\
\text { errors? }\end{array}$ & $\begin{array}{l}\text { "Results should be shared without naming } \\
\text { or blaming any individual." } \\
\text { "To emphasize that the role of IRS is to } \\
\text { detect and reduce errors and not to blame } \\
\text { individuals." } \\
\text { "To educate the staff that OVA (refers to } \\
\text { IRS) is not a platform for complaints, I have } \\
\text { seen some staff threatening other staff } \\
\text { that they will write OVA against them, so } \\
\text { all should understand that its target is to } \\
\text { improve the system." } \\
\text { "Protect people who report, minimize } \\
\text { routine reporting of daily issues, share the } \\
\text { lessons learned." } \\
\text { "Discussing, giving feedback, training." } \\
\text { "It comes from the top of the pyramid; } \\
\text { trainees should feel safe and supported." } \\
\text { "It starts with the leadership; they should } \\
\text { encourage juniors to be vigilant and feel } \\
\text { free to raise concerns whenever they arise." }\end{array}$ \\
\hline
\end{tabular}

Abbreviations: IRS, incident reporting system; OVA, occupational violence and aggression.

\section{Promoting Blame-Free Culture}

The study explored other suggestions from the participants ( - Table 3). In an analysis of the free-text responses, the participants stressed the need for a safe reporting environment. They also discussed the need to have nonpunitive actions that target sharing learnings from mistakes.

Additionally, the importance of role modeling by seniors was stressed by junior staff, while senior staff stressed the importance of role modeling by hospital leaders. Many participants called for a need for constant feedback provision.

The participants highlighted the need to raise awareness about the positive aspects of reporting and its importance to improve patient care. Finally, few participants explored the option of involving physicians in regular IR review committees to observe the whole process (- Table 3 ).

\section{Discussion}

Many studies highlighted incidents' underreporting in health care. ${ }^{6,14,15}$ Evidence suggested that physicians report significantly less compared with other health care providers. ${ }^{9,10}$ Furthermore, there is an unresolved uncertainty about the exact nature of what needs to be reported. ${ }^{15,16}$ All these add to the complexity and challenges of the IR process.

Our study attempted to assess IRS practice and knowledge, identify the perceived barriers to reporting incidents among internists, and identify possible solutions to overcome these barriers. The need for the study was pressing, as we needed to get an insight into our unique population of internists' behavior with regard to IRS and interpret this in the context of available international data.

We found a substantial physicians' proportion unaware of the availability of the IRS (41\%). Furthermore, they were not aware of the IR submission process (71\%) or have never submitted an IR report (80\%). This denotes significant underreporting and lack of awareness. Interestingly, almost two-thirds were less likely to report an IR when a colleague is involved in an incident. Findings from two previous studies showed a similar reporting rate among physicians (20\%) and trainees (43\%). ${ }^{6,17}$ In our study, we did not find significant differences between faculty and trainee responses, but this could be due to our small sample.

The main barriers of IR in our survey were unawareness and assumed complexity. In our institute, the system utilized and its process are relatively simple. However, this perception can only be changed by active demonstration and training, which participants felt might help increase the utilization of IRS coupled with shortening its process. A short teaching program was recently shown to be effective in improving the knowledge and practice of IR among medical trainees. ${ }^{18}$ Concerns highlighted by our participants, such as the need for dissemination of IR results or learning, were stressed earlier by the Mitchell et al paper which stated: "Ideally, following the investigation of a report, feedback from the analysis would be delivered to the reporters as well as to relevant people in the organization to close the loop." ${ }^{12}$

Assessment of the individual study participants' responses revealed that the concern of anonymity breach and the fear of retaliation stood as the most prevalent other barriers. These concerns were prevalent among previous studies attempted to study IR behaviors. ${ }^{6,14,16,19-21}$ To help overcome this, the participants in our survey demanded promoting safe culture for reporting by maintaining anonymity (our local IRS system ensures anonymity), reassuring the nonpunitive nature, and stressing the role of leadership and senior role modeling.

One of the strengths of our study is that it is the first to examine IR practices and barriers targeting internists only. Our study had $75 \%$ trainees since our institute is an academic institute; thus, the results can perhaps be used in similar educational settings. Finally, this study is the first study in Qatar and one of a few in the region exploring the IRS; we 
think that it will add significant knowledge to the international literature about the Middle East region, especially since the findings are nondiscrepant from the international data. $^{22-24}$

Our study is not without limitations. The study was conducted in a single corporate and country; hence, its findings may not fully capture IRS behaviors in other populations. Nevertheless, the diversity of our staff and the alignment of our study results with international data makes this less concerning. Additionally, our study by design did not include other health care professionals or other specialties, which could have provided a broader picture of the difference in reporting between health care professionals. It was limited to internal medicine physicians, as one of the aims was to incorporate the results of this survey in a future local quality improvement initiative. The response rate, although adequate, cannot rule out the possibility of a nonresponse bias, especially since the response rate from peripheral hospitals was suboptimal. Moreover, self-reporting is inherently flawed and may not accurately and objectively quantify the magnitude of the problem being assessed. Finally, the small sample limited further meaningful analysis and may have masked differences between trainees and attendings with regard to IR behaviors and practice. Nonetheless, there were no apparent differences when looking at crude percentages, except for training preferences.

\section{Conclusion}

Internal medicine physicians underutilize the IRS. Lack of awareness and training, insecurity, and fear of blame or retaliation are the main barriers to reporting incidents. Training, orientation, promoting a safe, no-blame, nonpunitive culture, sharing learnings, and providing feedback are all means of improving the utilization of the IRS. Hospital leaders should be involved in any effort aimed at improving incident reporting.

\section{Author Contribution}

A.E., M.F.H.M., and A.A. conceived the idea. M.F.H.M. and A.E. created the first draft questionnaire that was reviewed by I.Y., A.A., and the expert panel. After approval of the questionnaire, I.Y. disseminated the questionnaire to the target population. M.F.H.M. analyzed the results and drafted the tables and the manuscript. Then, the manuscript was reviewed by A.E.. and I.Y. Finally, the revised manuscript was sent to all the authors. All authors revised the manuscript and approved the final version for publication.

\section{Discloser}

The manuscript is currently not submitted for publication to other journal; however, a previous version was published on a preprint server and the link is provided (https://www.researchsquare.com/article/rs-6372/v1). All authors approved the manuscript.

Funding

None.

\section{Conflict of interest}

There are no conflicts of interest.

\section{Acknowledgment}

The authors would like to thank and acknowledge Dr. Akhnuwkh Jones and Dr. Mukesh Thakur (Sr. Consultants of General Internal Medicine, HMC) for their efforts in reviewing and validating the study questionnaire.

\section{References}

1 GLOSSARY - ICH GCP. Available at: https://ichgcp.net/1-glossary/. Accessed February 11, 2020

2 de Vries EN, Ramrattan MA, Smorenburg SM, Gouma DJ, Boermeester MA. The incidence and nature of in-hospital adverse events: a systematic review. Qual Saf Health Care 2008;17(3):216-223

3 Havens DH, Boroughs L. "To err is human": a report from the Institute of Medicine. J Pediatr Health Care 2000;14(2):77-80

4 WHO Draft GuiDelines fOr ADverse Event RepOrtinG anD LearninG Systems.; 2005 . Available at: https://apps.who.int/ iris/handle/10665/69797. Accessed April 5, 2021

5 Morag I, Gopher D, Spillinger A, et al. Human factors-focused reporting system for improving care quality and safety in hospital wards. Hum Factors 2012;54(2):195-213

6 Harper ML, Helmreich RL. Identifying barriers to the success of a reporting system. agency for healthcare research and quality (US). Availabe at: http://www.ncbi.nlm.nih.gov/ pubmed/21249983. Accessed December 24, 2018

7 Vincent C, Stanhope N, Crowley-Murphy M. Reasons for not reporting adverse incidents: an empirical study. J Eval Clin Pract 1999;5(1):13-21

8 Barach P, Small SD. Reporting and preventing medical mishaps: lessons from non-medical near miss reporting systems. BMJ 2000;320(7237):759-763

9 Nguyen Q-T, Weinberg J, Hilborne LH. Physician event reporting: training the next generation of physicians. Available at: http://www.ncbi.nlm.nih.gov/pubmed/21250010. Accessed December 30, 2018

10 Tuttle D, Holloway R, Baird T, Sheehan B, Skelton WK. Electronic reporting to improve patient safety. Qual Saf Health Care 2004;13(4):281-286

11 Bagenal J, Sahnan K, Shantikumar S. Comparing the attitudes and knowledge toward incident reporting in junior physicians and nurses in a district general hospital. J Patient Saf 2016;12(1):51-53

12 Mitchell I, Schuster A, Smith K, Pronovost P, Wu A. Patient safety incident reporting: a qualitative study of thoughts and perceptions of experts 15 years after 'To Err is Human' BMJ Qual Saf 2016;25(2):92-99

13 Perez B, Knych SA, Weaver SJ, et al. Understanding the barriers to physician error reporting and disclosure: a systemic approach to a systemic problem. J Patient Saf 2014;10(1):45-51

14 Nabors C, Peterson SJ, Aronow WS, et al. Physician reporting of clinically significant events through a computerized patient sign-out system. J Patient Saf 2011;7(3):155-161

15 Espin S, Carter C, Janes N, McAllister M. Exploring health care professionals' perceptions of incidents and incident reporting in rehabilitation settings. J Patient Saf 2019;15(2):154-160

16 Naome T, James M, Christine A, Mugisha TI. Practice, perceived barriers and motivating factors to medical-incident reporting: a cross-section survey of health care providers at Mbarara regional referral hospital, southwestern Uganda. BMC Health Serv Res 2020;20(1):276 
17 Hatoun J, Suen W, Liu C, et al. Elucidating reasons for resident underutilization of electronic adverse event reporting. Am J Med Qual 2016;31(4):308-314

18 Valery J, Helmi H, Spaulding A, et al. Video intervention to improve incident reporting among medical trainees. BMJ Open Qual 2019;8(4):e000706

19 Bovis JL, Edwin JP, Bano CP, Tyraskis A, Baskaran D, Karuppaiah K. Barriers to staff reporting adverse incidents in NHS hospitals. Future Healthc J 2018;5(2):117-120

20 Hamed MM, Konstantinidis S. Barriers to incident reporting among nurses: a qualitative systematic review. Western Journal of Nursing Research 2021;(e-pub ahead of print). doi:101177/0193945921999449
21 Alves MFT, Carvalho DS, Albuquerque GSC. Barriers to patient safety incident reporting by Brazilian health professionals: an integrative review. Cien Saude Colet 2019;24(8):2895-2908

22 Home. Available at: https://www.hamad.qa/EN/About-Us/ Pages/default.aspx. Accessed February 15, 2019

23 Rashed A, Hamdan M. Physicians' and nurses' perceptions of and attitudes toward incident reporting in Palestinian hospitals. J Patient Saf 2019;15(3):212-217

24 Hammoudi BM, Ismaile S, Abu Yahya O. Factors associated with medication administration errors and why nurses fail to report them. Scand J Caring Sci 2018;32(3):1038-1046 